\title{
A bioenergetic assessment of photosynthetic growth of Synechocystis sp. PCC 6803 in continuous cultures
}

\author{
Eleftherios Touloupakis, Bernardo Cicchi and Giuseppe Torzillo*
}

\begin{abstract}
Background: Synechocystis sp. PCC 6803, a model organism used for bioenergy and bioplastic production, was grown in continuous culture to assess its most important bioenergetic parameters.

Results: Biomass yield on light energy of $1.237 \mathrm{~g} \mathrm{~mol} \mathrm{photons}^{-1}$ and maintenance energy requirement of $0.00312 \mathrm{~mol}$ photons $\mathrm{g}^{-1} \mathrm{~h}^{-1}$ were calculated. This corresponded to a light conversion efficiency of $12.5 \%$, based on the model of Pirt which was about $35 \%$ lower than the theoretical one based on the stoichiometric equation for the formation of biomass on carbon dioxide, water, and nitrate. The maximum $F_{\mathrm{v}} / F_{\mathrm{m}}$ ratio recorded in the Synechocystis cultures was 0.57 ; it progressively declined to 0.45 as the dilution rate increased. An over-reduction of reaction centers at a high dilution rate was also recorded, together with an increased $V$, phase for the chlorophyll fluorescence transient. In contrast, the chlorophyll optical cross section increased by about $40 \%$ at the fastest dilution rate, and compensated for the decline in $F_{\mathrm{v}} / F_{m^{\prime}}$ thus resulting in a constant total photosynthesis rate (photosynthesis plus respiration). Chlorophyll content was maximum at the lowest dilution rate and was $48 \%$ lower at the highest one, while phycocyanin, and total carotenoids decreased by about $42 \%$ and $37 \%$, respectively. Carotenoid analysis revealed increased echinenone, zeaxanthin, and myxoxanthophyll contents as the dilution rate increased (40.6, 63.8 and $35.5 \%$, respectively, at the fastest dilution rate). A biochemical analysis of the biomass harvested at each different dilution rates showed no changes in the lipid content (averaging $11.2 \pm 0.6 \%$ of the dry weight), while the protein content decreased as the dilution rate increased, ranging between $60.7 \pm 1.1$ and $72.6 \pm 0.6 \%$. Amino acids pattern did not vary with the dilution rate. Carbohydrate content ranged from 9.4 to $16.2 \%$ with a mean value of $11.2 \pm 1.4 \%$.

Conclusions: The present work provides useful information on the threshold of light conversion efficiency in Synechocystis, as well as basic bioenergetic parameters that will be helpful for future studies related to its genetic transformation and metabolic network reconstruction.
\end{abstract}

Keywords: Photobioreactor, Continuous culture, Cyanobacteria, Light conversion efficiency (LCE), Fluorescence

\section{Background}

The cyanobacterium Synechocystis sp PCC 6803 (hereafter Synechocystis) is widely used as a model organism for the study of photosynthetic processes, since it can easily be transformed and is well characterized. Its genome is completely sequenced, and a variety of mutants is available. The use of Synechocystis has been proposed for the production of biofuels and also for that of chemicals and

\footnotetext{
*Correspondence: torzillo@ise.cnrit

Istituto per lo Studio degli Ecosistemi, CNR, Sede di Firenze, Via Madonna del Piano, 10, 50019 Sesto Fiorentino, Italy
}

biomaterials [1-3]. Recent studies have demonstrated that Synechocystis is a good candidate organism for photobiological hydrogen production [4]. It has been genetically engineered for the photosynthetic production of isoprene hydrocarbon currently used as feedstock in the synthetic chemistry industry for the production of commercial commodities [5-7].

Understanding the dependence of Synechocystis growth on light absorption is a pre-requisite for achieving (a) high photosynthetic efficiency, (b) future genetic manipulation and (c) scaling-up of cultures outdoors. For these 
purposes, continuous cultures operated at steady state present several advantages, including constant growth rates and a constant biomass composition for extended time periods [8]. Indeed, whether Synechocystis is a wild type or a genetically modified strain, the enhancement of its productivity will depend on identifying constraints on its growth and upon overcoming those limitations with well-designed photobioreactors (PBR) $[9,10]$.

In this study, we used a flat-bed PBR to assess the bioenergetics of photosynthetic growth of Synechocystis in continuous cultures. To this end, the cultures were subjected to different dilution rates, which established conditions ranging from light limitation to light saturation.

\section{Results}

\section{Culture characterization}

The dependence of cell concentration on the dilution rate $(D)$ is shown in Fig. 1a. The maximum cell concentration of the culture at the steady state was $632 \pm 12 \mathrm{mg} \mathrm{L}^{-1}$, and it decreased to $75 \pm 0 \mathrm{mg} \mathrm{L}^{-1}$ at the highest $D$. Productivity values at different $D$ are shown in Fig. $1 \mathrm{~b}$ and Table 1 . The highest culture productivity was $11.30 \pm 0.15 \mathrm{mg} \mathrm{h}^{-1}$, recorded at $D=0.055 \mathrm{~h}^{-1}$, while the lowest value of productivity, $8.44 \pm 0.54 \mathrm{mg} \mathrm{h}^{-1}$, was found at $D=0.1184 \mathrm{~h}^{-1}$, close to wash-out. It was, therefore, assumed to be the maximum growth rate of the culture, corresponding to a minimum doubling time of $5.8 \mathrm{~h}$ (Table 1; Fig. 1).

The growth yield $Y_{\mathrm{kJ}}$ (the amount of dry biomass synthesized per kJ of light energy absorbed) was rather constant along the dilution rate with a mean value of $5.18 \pm 0.29 \mathrm{mg} \mathrm{kJ}^{-1}$ (Table 1).

By multiplying $Y_{\mathrm{kJ}}$ values, attained at each $D$, by the heat of combustion of the biomass, it was possible to estimate the apparent light conversion efficiency (LCE). The average heat of combustion of the biomass was $21.98 \pm 1.05 \mathrm{~kJ} \mathrm{~g}^{-1}$. The mean LCE resulted close to $11.32 \pm 0.41 \%$ at all the $D$ tested (Table 1 ).

\section{Fluorescence and photosynthetic parameters}

The maximum quantum yield of PSII was measured at the various $D ; F_{\mathrm{v}} / F_{\mathrm{m}}$ decreased as $D$ increased (Additional file 1: Figure S1). This reflects the fact that, at the highest $D$, the cells experienced higher light exposure, which led to a down-regulation of PSII of about $21.5 \%$. The highest value of $F_{\mathrm{v}} / F_{\mathrm{m}}$ recorded in this study was 0.572 (Table 2).

The fluorescence, $F_{\mathrm{s}}$, and the maximum fluorescence, $F_{\mathrm{m}}{ }^{\prime}$, i.e., in the light-adapted state, were monitored during the steady state of the culture, and the effective photochemical quantum yield of PSII $\left(\Delta F / F_{\mathrm{m}}{ }^{\prime}\right)$ was determined by performing in situ measurements under illumination. The effective quantum yield of PSII $\left(\Delta F / F_{\mathrm{m}}{ }^{\prime}\right)$ decreased as $D$ increased (increment in light exposure per cell), following the same trend as the $F_{\mathrm{v}} / F_{\mathrm{m}}$ ratio. The overall decrease in the $\Delta F / F_{\mathrm{m}}{ }^{\prime}$ of the cells was $23.5 \%$ (Table 2).

The mean value of $\Phi_{\mathrm{CO} 2}$ was $0.0533 \pm 0.0047$ $\left(\mathrm{mol} \mathrm{CO}_{2}\right.$ mol photons $^{-1}$ ) with a difference between the lowest and highest dilution rates of about $20 \%$ (Table 2).

NPQ values of chlorophyll fluorescence were found to be very low at all $D$, indicating a low level of energy dissipation. Accordingly, the $\mathrm{qP}$ values were relatively high, constantly between 0.8 and 0.9 , indicating that the fraction of PSII reaction centers that were open and capable of photochemistry was high in all the tested dilution rates.

Chlorophyll fluorescence-induction kinetics (OJIP) were measured in each experiment. The transient
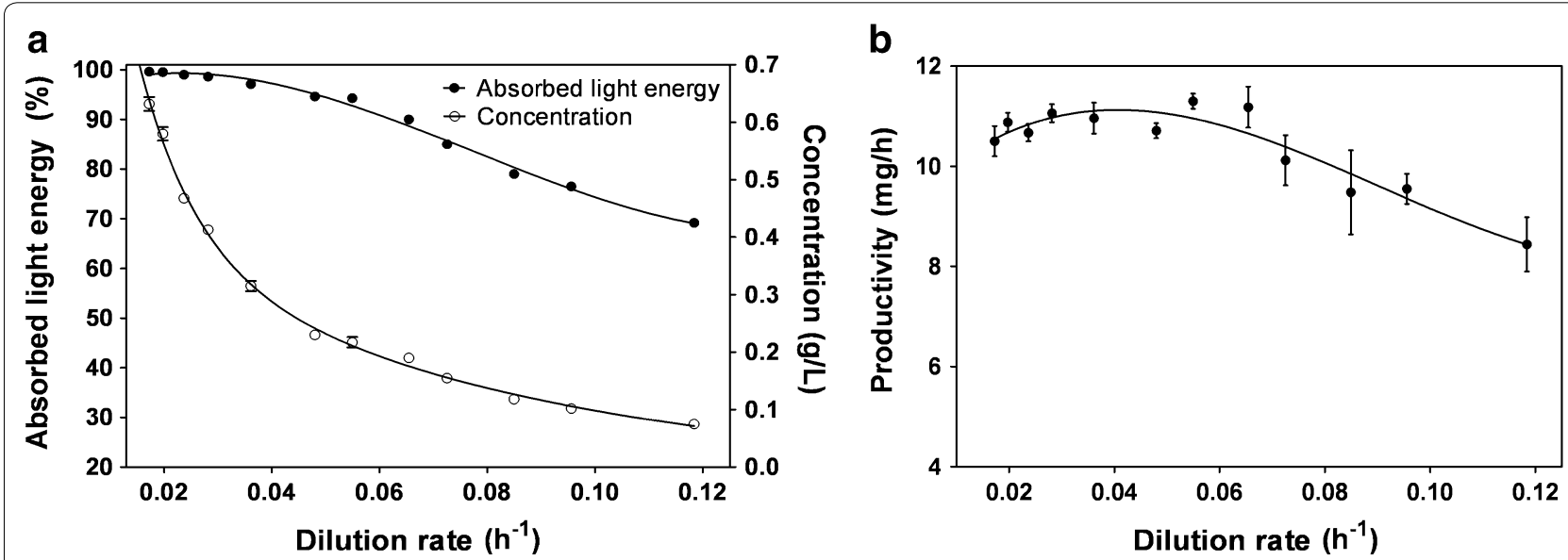

Fig. 1 a Relationship between light energy absorption, as a function of the dilution rate; $\mathbf{b}$ changes in productivity as a function of the dilution rate during the Synechocystis cultivations. Data are the average from at least three measurements; error bars represent the standard deviations 
Table 1 Cell concentration, light absorption, productivity, growth yield, actual biomass yield on light energy $(Y)$ and light conversion efficiency (LCE) of Synechocystis in a continuous culture

\begin{tabular}{|c|c|c|c|c|c|c|c|c|}
\hline$D\left(\mathrm{~h}^{-1}\right)$ & $\begin{array}{l}\text { Concentration } \\
\left(\mathrm{mg} \mathrm{L}^{-1}\right)\end{array}$ & $\begin{array}{l}\text { Absorbed light } \\
\text { (\%) }\end{array}$ & $\begin{array}{l}\text { Productivity } \\
\left(\mathrm{mg} \mathrm{h}^{-1}\right)\end{array}$ & $Y_{\mathrm{kJ}}\left(\mathrm{g} \mathrm{kJ}^{-1} \times 10^{-3}\right)$ & $Y_{\mathrm{kJ}}\left(\mathrm{g} \mathrm{kJ}^{-1} \times 10^{-3}\right)^{\mathrm{a}}$ & $\begin{array}{l}Y(\mathrm{~g} \mathrm{~mol} \text { pho- } \\
\left.\text { tons }{ }^{-1}\right)\end{array}$ & LCE (\%) & $\operatorname{LCE}(\%)^{a}$ \\
\hline 0.0173 & $632 \pm 12$ & 99.6 & $10.50 \pm 0.30$ & $4.71 \pm 0.13$ & $4.69 \pm 0.28$ & $1.02 \pm 0.02$ & $10.7 \pm 0.5$ & $10.5 \pm 0.6$ \\
\hline 0.0198 & $580 \pm 10$ & 99.5 & $10.88 \pm 0.19$ & $4.89 \pm 0.08$ & $4.86 \pm 0.21$ & $1.07 \pm 0.02$ & $10.7 \pm 0.3$ & $10.6 \pm 0.4$ \\
\hline 0.0237 & $468 \pm 3$ & 99.0 & $10.67 \pm 0.17$ & $4.82 \pm 0.17$ & $4.77 \pm 0.17$ & $1.04 \pm 0.01$ & $11.4 \pm 0.5$ & $11.3 \pm 0.5$ \\
\hline 0.0282 & $413 \pm 7$ & 98.6 & $11.06 \pm 0.18$ & $5.02 \pm 0.09$ & $4.94 \pm 0.55$ & $1.09 \pm 0.02$ & $11.1 \pm 0.7$ & $10.9 \pm 1.2$ \\
\hline 0.0361 & $315 \pm 9$ & 97.1 & $10.96 \pm 0.31$ & $5.05 \pm 0.10$ & $4.90 \pm 0.10$ & $1.08 \pm 0.03$ & $11.9 \pm 0.2$ & $11.6 \pm 0.2$ \\
\hline 0.0480 & $230 \pm 3$ & 94.6 & $10.71 \pm 0.15$ & $5.06 \pm 0.07$ & $4.79 \pm 0.25$ & $1.08 \pm 0.01$ & $11.0 \pm 0.6$ & $10.3 \pm 0.7$ \\
\hline 0.0550 & $217 \pm 9$ & 94.3 & $11.30 \pm 0.15$ & $5.36 \pm 0.13$ & $5.05 \pm 0.12$ & $1.17 \pm 0.05$ & $11.9 \pm 0.3$ & $11.1 \pm 0.3$ \\
\hline 0.0654 & $190 \pm 0$ & 90.0 & $11.18 \pm 0.41$ & $5.55 \pm 0.33$ & $5.00 \pm 0.49$ & $1.21 \pm 0.01$ & $11.6 \pm 0.9$ & $10.4 \pm 1.0$ \\
\hline 0.0725 & $155 \pm 7$ & 85.0 & $10.12 \pm 0.50$ & $5.32 \pm 0.25$ & $4.52 \pm 0.21$ & $1.22 \pm 0.05$ & $11.7 \pm 0.6$ & $9.9 \pm 0.5$ \\
\hline 0.0849 & $118 \pm 5$ & 79.0 & $9.48 \pm 0.84$ & $5.36 \pm 0.29$ & $4.24 \pm 0.23$ & $1.17 \pm 0.05$ & $11.2 \pm 0.6$ & $8.9 \pm 0.5$ \\
\hline 0.0956 & $102 \pm 3$ & 76.5 & $9.55 \pm 0.30$ & $5.58 \pm 0.26$ & $4.27 \pm 0.20$ & $1.18 \pm 0.03$ & $11.4 \pm 0.4$ & $8.5 \pm 0.3$ \\
\hline 0.1184 & $75 \pm 0$ & 69.2 & $8.44 \pm 0.54$ & $5.45 \pm 0.12$ & $3.77 \pm 0.08$ & $1.19 \pm 0.01$ & $11.2 \pm 0.2$ & $7.7 \pm 0.2$ \\
\hline
\end{tabular}

Values are mean \pm standard deviations calculated during the steady state at each dilution rate

a When considering total light absorption

Table 2 Maximum quantum efficiency of PSII photochemistry $\left(F_{v} / F_{m}\right)$, effective photochemical quantum yield of PSII $\left(\Delta F / F_{m}\right)$, effective efficiency of PSII photochemistry $\left(F_{v}{ }^{\prime} / F_{m}{ }^{\prime}\right)$, non-photochemical quenching (NPQ), photochemical quenching (qP), and quantum yield of $\mathrm{CO}_{2}$ assimilation $\left(\Phi_{\mathrm{CO} 2}\right)$ of Synechocystis in a continuous culture

\begin{tabular}{|c|c|c|c|c|c|c|}
\hline$D\left(\mathrm{~h}^{-1}\right)$ & $F_{\mathrm{v}} / F_{\mathrm{m}}$ & $\Delta F / F_{\mathrm{m}}{ }^{\prime}$ & $F_{\mathrm{v}}^{\prime} / F_{\mathrm{m}}^{\prime}$ & NPQ & QP & $\Phi_{\mathrm{CO} 2}$ \\
\hline 0.0173 & $0.572 \pm 0.006$ & $0.464 \pm 0.009$ & $0.551 \pm 0.001$ & $0.10 \pm 0.02$ & $0.84 \pm 0.01$ & $0.058 \pm 0.001$ \\
\hline 0.0198 & $0.564 \pm 0.008$ & $0.485 \pm 0.001$ & $0.548 \pm 0.001$ & $0.06 \pm 0.02$ & $0.89 \pm 0.02$ & $0.060 \pm 0.000$ \\
\hline 0.0237 & $0.572 \pm 0.013$ & $0.474 \pm 0.008$ & $0.555 \pm 0.002$ & $0.11 \pm 0.01$ & $0.86 \pm 0.03$ & $0.059 \pm 0.001$ \\
\hline 0.0282 & $0.549 \pm 0.004$ & $0.458 \pm 0.003$ & $0.522 \pm 0.006$ & $0.11 \pm 0.01$ & $0.88 \pm 0.01$ & $0.057 \pm 0.001$ \\
\hline 0.0361 & $0.525 \pm 0.011$ & $0.451 \pm 0.002$ & $0.501 \pm 0.007$ & $0.06 \pm 0.05$ & $0.89 \pm 0.16$ & $0.056 \pm 0.002$ \\
\hline 0.0480 & $0.514 \pm 0.010$ & $0.443 \pm 0.017$ & $0.493 \pm 0.004$ & $0.10 \pm 0.03$ & $0.90 \pm 0.06$ & $0.055 \pm 0.000$ \\
\hline 0.0550 & $0.510 \pm 0.004$ & $0.411 \pm 0.001$ & $0.492 \pm 0.006$ & $0.11 \pm 0.02$ & $0.83 \pm 0.14$ & $0.051 \pm 0.000$ \\
\hline 0.0654 & $0.506 \pm 0.016$ & $0.417 \pm 0.001$ & $0.467 \pm 0.001$ & $0.11 \pm 0.00$ & $0.89 \pm 0.04$ & $0.052 \pm 0.000$ \\
\hline 0.0725 & $0.483 \pm 0.016$ & $0.400 \pm 0.003$ & $0.468 \pm 0.001$ & $0.07 \pm 0.00$ & $0.87 \pm 0.04$ & $0.050 \pm 0.000$ \\
\hline 0.0849 & $0.476 \pm 0.000$ & $0.390 \pm 0.001$ & $0.448 \pm 0.000$ & $0.11 \pm 0.00$ & $0.87 \pm 0.01$ & $0.048 \pm 0.000$ \\
\hline 0.0956 & $0.452 \pm 0.011$ & $0.388 \pm 0.012$ & $0.434 \pm 0.001$ & $0.08 \pm 0.02$ & $0.90 \pm 0.02$ & $0.048 \pm 0.001$ \\
\hline 0.1184 & $0.450 \pm 0.001$ & $0.371 \pm 0.000$ & $0.433 \pm 0.001$ & $0.08 \pm 0.02$ & $0.84 \pm 0.09$ & $0.046 \pm 0.000$ \\
\hline
\end{tabular}

Values are mean \pm standard deviations calculated over the steady state for each dilution rate

followed the typical polyphasic OJIP rise (Fig. 2). At higher $D$ values $M_{0}$ and $V_{\mathrm{J}}$ values increased, indicating a higher rate of closure of the reaction centers and an increment in the net rate of $Q_{\mathrm{A}}$ reduction (Additional file 2: Table S1). The values of $\Psi_{0}$ (probability that a trapped electron can move further ahead than $Q_{\mathrm{A}}^{-}$) and $\Phi_{\mathrm{E} 0}$ diminished by 25 and $43 \%$ compared to the lowest $D$ values, respectively, evidencing a reduction in the efficiency of PSII to perform photosynthesis, which caused the observed reduction in culture productivity (Additional file 2: Table S1). At increasing $D$ values, $S_{\mathrm{m}}$ decreased, overall by $10 \%$, indicating a decrease in the size of functional PQ pool.
The overall linear electron transport rate (ETR) was also determined at the steady state of the culture in each experiment (Table 3). The highest ETR value, $0.425 \pm 0.001 \mu \mathrm{mol} \mathrm{e} \mathrm{e}^{-} \mathrm{mg} \mathrm{chl} \mathrm{c}^{-1} \mathrm{~s}^{-1}$, was found at $D=0.0198 \mathrm{~h}^{-1}$, and this value decreased by $18 \%$ at the highest dilution rate.

Oxygen evolution and respiration rates changes in response to the different $D$ were analyzed (Table 3 ). The net oxygen evolution rate of Synechocystis cells ranged between $270 \mu \mathrm{mol} \mathrm{O} \mathrm{mg} \mathrm{chl}^{-1} \mathrm{~h}^{-1}$ at the highest $D$, to more than $300 \mu \mathrm{mol} \mathrm{O} \mathrm{mg} \mathrm{chl}^{-1} \mathrm{~h}^{-1}$, in cells grown at lower $D$ (between 0.0173 and $0.0654 \mathrm{~h}^{-1}$ ). Comparing the lowest and highest $D$ values, respiration rates increased 


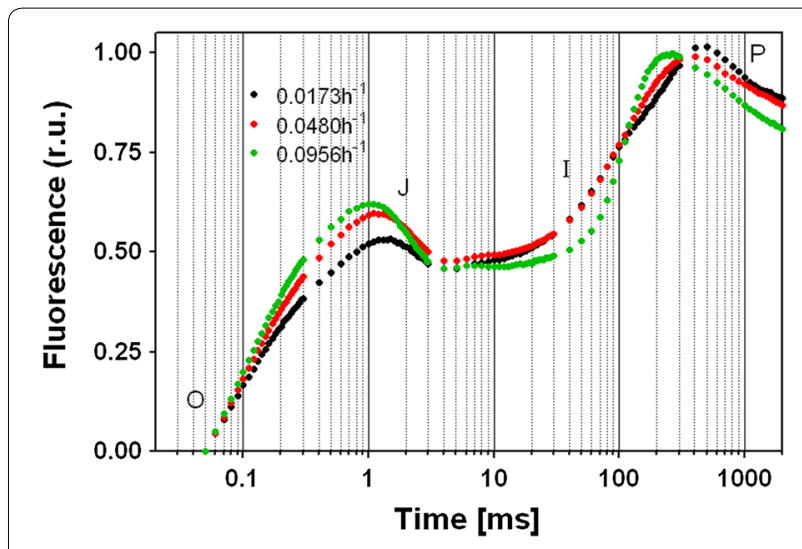

Fig. 2 Effect of the dilution rates on chlorophyll a fluorescence transients. Initial fluorescence values were set at zero, and fluorescence values were normalized to maximum fluorescence

$6.5 \times$ times (Table 3). Respiration increased at high dilution rates, where light availability per cell was higher. Consequently, the mean gross oxygen evolution (net oxygen evolution plus respiration) did not differ much at different $D$ remaining close to $352 \pm 23 \mu \mathrm{mol} \mathrm{O}_{2}$ $\mathrm{mg} \mathrm{Chl}{ }^{-1} \mathrm{~h}^{-1}$.

\section{Biomass characterization}

The chemical biomass composition of the cultures was determined in order to analyze its relationship with dilution rates.

\section{Elemental analysis}

Additional file 3: Table S2 shows the elemental composition (\% DW) of the dried biomass of Synechocystis cells harvested at the steady-state at each $D$. The carbon and hydrogen contents were higher at low $D$, due to a greater percentage of carbohydrates in the biomass: they ranged from $42.1 \pm 0.7$ to $47.6 \pm 0.1 \%$ and from $6.5 \pm 0.1$ to $7.3 \pm 0.2 \%$ of DW, respectively. Nitrogen and sulfur contents remained fairly stable, between $10.0 \pm 0.2$ and $11.1 \pm 0.4 \%$ and between $0.362 \pm 0.001$ and $0.442 \pm 0.014 \%$, respectively.

\section{Lipid, carbohydrate and protein contents}

Lipid content in the biomass (\% DW) was similar at all $D$ (Table 4 ): the average value was $11.2 \pm 0.6 \%$. Protein content decreased slightly as $D$ increased, ranging from $60.7 \pm 1.1$ to $72.6 \pm 0.6 \%$ with an average value of $65.0 \pm 3.6 \%$. Amino acid profile of cells grown at three different dilution rates $\left(0.0173,0.0654\right.$ and $\left.0.1184 \mathrm{~h}^{-1}\right)$ did not show relevant changes (Additional file 4: Table S3). Carbohydrate content ranged from 9.4 \pm 0.2 to $13.2 \pm 0.2 \%$, with an average of $11.2 \pm 1.4 \%$. The average ash content was $5.44 \pm 0.52 \%$.

\section{Photosynthetic pigments}

Phycocyanin (Pc) and allophycocyanin (Apc) contents were highest at the lowest $D$, and decreased by 42.5 and $58.6 \%$, respectively, at maximum $D$ (Table 4 ). The major carotenoids found in Synechocystis cells at the various $D$ values were $\beta$-carotene ( $\beta$-Car), myxoxanthophyll (Myx), zeaxanthin (Zea) and echinenon (Ech). Increases of $40.6 \%$ in Ech and of $63.8 \%$ in Zea were observed between minimum and maximum $\mathrm{D}$, while the Myx increase was slightly lower (35.5 \%) (Fig. 3). The chlorophyll a content decreased linearly as the $D$ increased. The overall decrease was $47.6 \%$ at the highest $D$ value. On the contrary, cells grown at low $D$ showed a higher chlorophyll content.

Table 3 Chlorophyll optical absorption cross-section ( $\left.a^{*}\right)$, maximum electron transfer rate $\left(E T R_{\text {max }}\right), O_{2}$ evolution and respiration rates of Synechocystis in a continuous culture

\begin{tabular}{|c|c|c|c|c|}
\hline$D\left(\mathrm{~h}^{-1}\right)$ & $\begin{array}{l}\text { Net } \mathrm{O}_{2} \text { evolution } \\
\left(\mu \mathrm{mol} \mathrm{O}_{2} \mathrm{mg} \mathrm{chl}^{-1} \mathrm{~h}^{-1}\right)\end{array}$ & $\begin{array}{l}\text { Respiration } \\
\left(\mu \mathrm{mol} \mathrm{O}_{2} \mathrm{mg} \mathrm{chl}^{-1} \mathrm{~h}^{-1}\right)\end{array}$ & $a^{*}\left(\mathrm{~m}^{2} \mathrm{mg} \mathrm{chl}^{-1}\right)$ & $\begin{array}{l}\text { ETR }\left(\mu \mathrm{mol} \mathrm{e}^{-} \mathrm{mg}\right. \\
\left.\mathrm{chl}^{-1} \mathrm{~s}^{-1}\right)\end{array}$ \\
\hline 0.0173 & $299 \pm 6(314 \pm 7)$ & $15 \pm 1$ & $0.0112 \pm 0.0003$ & $0.386 \pm 0.007$ \\
\hline 0.0198 & $329 \pm 1(349 \pm 3)$ & $20 \pm 2$ & $0.0118 \pm 0.0005$ & $0.425 \pm 0.001$ \\
\hline 0.0237 & $322 \pm 5(361 \pm 6)$ & $38 \pm 1$ & $0.0118 \pm 0.0005$ & $0.416 \pm 0.007$ \\
\hline 0.0282 & $313 \pm 2(359 \pm 4)$ & $46 \pm 2$ & $0.0120 \pm 0.0002$ & $0.404 \pm 0.002$ \\
\hline 0.0361 & $327 \pm 1(393 \pm 13)$ & $66 \pm 12$ & $0.0129 \pm 0.0003$ & $0.423 \pm 0.002$ \\
\hline 0.0480 & $319 \pm 12(374 \pm 19)$ & $55 \pm 7$ & $0.0131 \pm 0.0009$ & $0.411 \pm 0.015$ \\
\hline 0.0550 & $304 \pm 1(348 \pm 3)$ & $44 \pm 2$ & $0.0135 \pm 0.0005$ & $0.392 \pm 0.001$ \\
\hline 0.0654 & $300 \pm 1(352 \pm 2)$ & $52 \pm 1$ & $0.0138 \pm 0.0012$ & $0.387 \pm 0.001$ \\
\hline 0.0725 & $280 \pm 2(308 \pm 6)$ & $28 \pm 4$ & $0.0142 \pm 0.0002$ & $0.362 \pm 0.002$ \\
\hline 0.0849 & $273 \pm 1(343 \pm 2)$ & $70 \pm 1$ & $0.0152 \pm 0.0010$ & $0.352 \pm 0.001$ \\
\hline 0.0956 & $264 \pm 8(359 \pm 14)$ & $95 \pm 6$ & $0.0153 \pm 0.0007$ & $0.340 \pm 0.010$ \\
\hline 0.1184 & $271 \pm 0(369 \pm 9)$ & $98 \pm 9$ & $0.0182 \pm 0.0027$ & $0.349 \pm 0.000$ \\
\hline
\end{tabular}

Values are mean \pm standard deviations calculated over the steady state for each dilution rate. In parenthesis, total evolution (net oxygen evolution plus respiration) 
Table 4 Lipid, carbohydrate, protein, phycocyanin (Pc), allophycocyanin (Apc) and chlorophyll a (ChI) contents of Synechocystis dried biomass, cultured at different dilution rates

\begin{tabular}{|c|c|c|c|c|c|c|}
\hline$D\left(\mathrm{~h}^{-1}\right)$ & Lipids (\%) & Carbohydrates (\%) & Proteins (\%) & Pc (\%) & Apc (\%) & Chl (\%) \\
\hline 0.0173 & $11.5 \pm 0.2$ & $11.0 \pm 1.1$ & $66.1 \pm 2.5$ & $19.6 \pm 1.3$ & $5.12 \pm 029$ & $2.33 \pm 0.06$ \\
\hline 0.0198 & $11.6 \pm 1.7$ & $13.2 \pm 0.2$ & $62.7 \pm 0.8$ & $18.9 \pm 1.1$ & $4.56 \pm 0.14$ & $2.27 \pm 0.09$ \\
\hline 0.0237 & $11.6 \pm 1.6$ & $12.9 \pm 0.4$ & $71.2 \pm 1.5$ & $19.2 \pm 0.2$ & $4.26 \pm 0.21$ & $2.29 \pm 0.09$ \\
\hline 0.0282 & $12.0 \pm 0.6$ & $11.7 \pm 0.7$ & $64.7 \pm 7.0$ & $18.1 \pm 0.8$ & $3.97 \pm 0.02$ & $2.11 \pm 0.04$ \\
\hline 0.0361 & $10.6 \pm 0.9$ & $12.5 \pm 0.0$ & $72.6 \pm 0.6$ & $17.9 \pm 2.6$ & $4.94 \pm 0.09$ & $2.24 \pm 0.05$ \\
\hline 0.0480 & $11.0 \pm 1.8$ & $11.9 \pm 0.6$ & $64.8 \pm 4.5$ & $14.9 \pm 1.3$ & $2.49 \pm 0.35$ & $2.13 \pm 0.14$ \\
\hline 0.0550 & $11.7 \pm 0.6$ & $12.5 \pm 0.3$ & $64.7 \pm 1.2$ & $15.4 \pm 0.3$ & $2.18 \pm 0.20$ & $2.11 \pm 0.08$ \\
\hline 0.0654 & $11.7 \pm 0.2$ & $9.5 \pm 1.0$ & $61.2 \pm 7.4$ & $13.0 \pm 1.0$ & $1.95 \pm 0.76$ & $1.64 \pm 0.14$ \\
\hline 0.0725 & $11.9 \pm 0.2$ & $10.7 \pm 0.6$ & $65.0 \pm 2.1$ & $13.0 \pm 2.1$ & $1.92 \pm 0.99$ & $1.84 \pm 0.02$ \\
\hline 0.0849 & $10.5 \pm 0.6$ & $9.4 \pm 0.2$ & $64.0 \pm 3.7$ & $10.3 \pm 0.9$ & $1.63 \pm 0.49$ & $1.60 \pm 0.11$ \\
\hline 0.0956 & $10.6 \pm 0.3$ & $10.2 \pm 0.4$ & $60.7 \pm 1.1$ & $10.9 \pm 1.0$ & $2.10 \pm 0.35$ & $1.48 \pm 0.07$ \\
\hline 0.1184 & $10.4 \pm 0.4$ & $9.6 \pm 0.7$ & $62.2 \pm 0.6$ & $11.3 \pm 1.4$ & $2.12 \pm 0.40$ & $1.22 \pm 0.18$ \\
\hline
\end{tabular}

Values are mean \pm standard deviations calculated during the steady state at each dilution rate

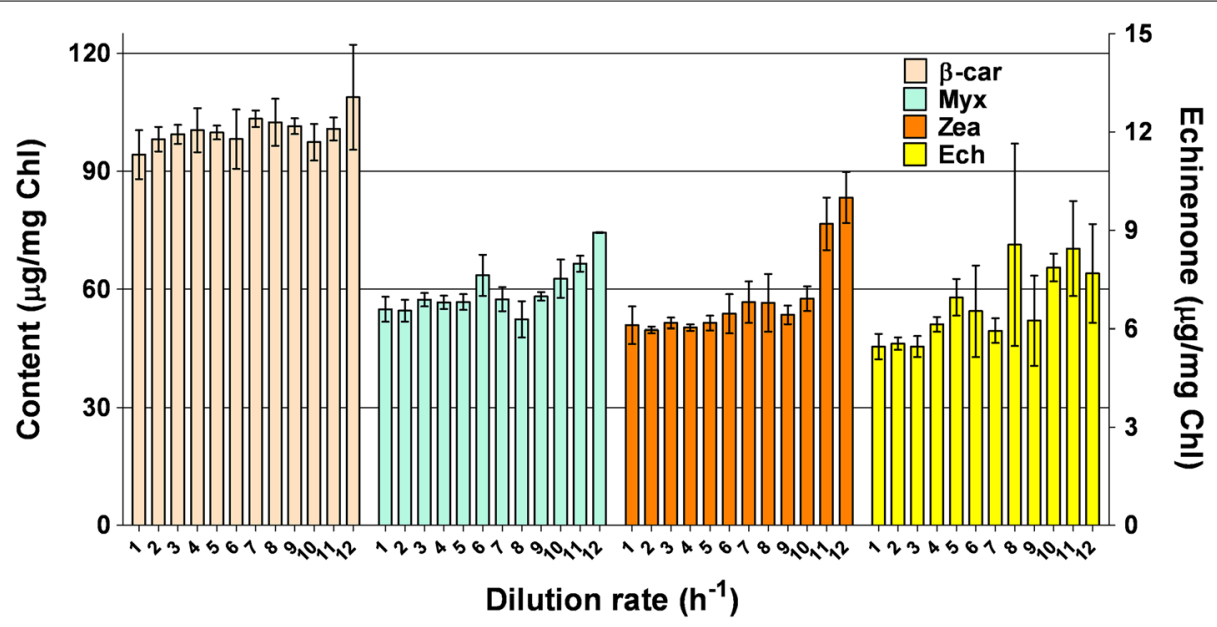

Fig. 3 Evolution of $\beta$-car, Myx, Zea and Ech over the various dilution rates: (1) $0.0173 \mathrm{~h}^{-1}$, (2) $0.0198 \mathrm{~h}^{-1}$, (3) $0.0237 \mathrm{~h}^{-1}$, (4) $0.0282 \mathrm{~h}^{-1}$, (5) $0.0361 \mathrm{~h}^{-1}$, (6) $0.048 \mathrm{~h}^{-1}$, (7) $0.055 \mathrm{~h}^{-1}$, (8) $0.0654 \mathrm{~h}^{-1}$, (9) $0.0725 \mathrm{~h}^{-1}$, (10) $0.0849 \mathrm{~h}^{-1}$, (11) $0.0956 \mathrm{~h}^{-1}$, (12) $0.1184 \mathrm{~h}^{-1}$

\section{Biomass yield on light energy}

The biomass yield $(Y)$ on light energy indicates the ability of photosynthetic microorganisms to use the light energy supplied for purposes of biomass formation. In general, the energy requirement of a light-limited culture with no dark zones can be expressed by the sum of two terms $[11,12]$ :

Energy absorbed = Energy for biomass formation + energy required for maintenance

$$
\phi \mathrm{PFD}=\mu \times X \times V / Y_{G}+m \times X \times V
$$

Hence,

$$
(\phi \mathrm{PFD} \times A) /(X \times V)=\mu / Y_{G}+m
$$

where the term on the left side is the specific light absorption rate $(\mathrm{qL}=\phi \mathrm{PFD} \times A / X \times V)$.
The actual biomass yield ( $\mathrm{Y}$ ), based on the biomass production rate $\left(\mathrm{g} \mathrm{L}^{-1} \mathrm{~h}^{-1}\right)$, and the light-absorbed rate $(\phi P F D)$ can be calculated by the following Eq. (3)

$$
\begin{aligned}
Y= & X \times \mu \times V /\left(\phi \mathrm{PFD} \times A \times 3600 \times 10^{-6}\right) \\
& \times\left(\text { g mol photons }^{-1}\right)
\end{aligned}
$$

The specific light rate absorbed by the culture layer is given by:

$$
\begin{aligned}
q L= & \phi P D F \times A /\left(X \times V \times 3600 \times 10^{-6}\right) \\
& \times\left(\text { mol photons } \mathrm{g}^{-1} \mathrm{~h}^{-1}\right)
\end{aligned}
$$

To assess the incidence of the maintenance energy requirement on the yield, we plotted our data following 
Pirt's model [12]. This model is based on a constant light energy requirement for maintenance, as well as on a constant energy requirement for the biomass formation, i.e.:

$$
\mathrm{qL} \times 0.0036=\mu / Y_{G}+m\left(\mathrm{~mol} \text { photons } \mathrm{g}^{-1} \mathrm{~h}^{-1}\right)
$$

By plotting the specific light-absorbed rate qL, i.e., the left-hand side of Eq. (5), versus the growth rates $(\mu)$ attained at the different biomass concentrations, a straight line should be obtained. The slope of this equation represents the inverse of the $Y_{\mathrm{G}}$ (maximum growth yield), and the intercept on the ordinate axes represents the maintenance coefficient $(m)$ (mol photons $\mathrm{g}^{-1} \mathrm{~h}^{-1}$ ). As can be seen in Fig. 4, both the yield and the maintenance coefficient requirement were constant. The following relation was found for Synechocystis:

$$
\begin{aligned}
\mathrm{qL} \times 0.0036= & \mu / 1.237+0.003117\left(R^{2}=0.9974\right) \\
& \times\left(\text { mol photons } \mathrm{g}^{-1} \mathrm{~h}^{-1}\right)
\end{aligned}
$$

Based on Pirt's model, a constant biomass yield on the absorbed light energy of $1.237 \mathrm{~g} \mathrm{~mol} \mathrm{photons}^{-1}$ was calculated for Synechocystis. This yield value was found to be about $35 \%$ lower than the theoretical one (Additional file 5: Text S1).

\section{Discussion}

Since there is considerable interest throughout the world in exploring Synechocystis as both an organism suitable for producing hydrogen and as a source of bioplastic material, an assessment of its photosynthetic efficiency is important. To determine the optimum growth conditions of Synechocystis, continuous culture experiments

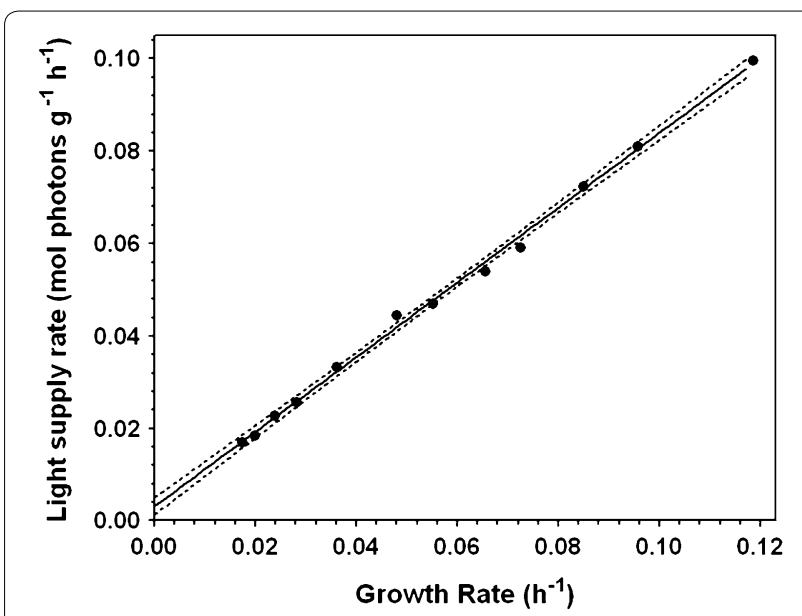

Fig. 4 Specific light-absorbed rate by the culture as a function of growth rate. The dashed lines delimit the $95 \%$ confidence intervals were carried out. Different dilution rates were applied to establish the optimal cell concentration and the maximal light conversion attainable by this organism.

A constant biomass yield on the absorbed light energy of $1.237 \mathrm{~g} \mathrm{~mol} \mathrm{photons}^{-1}$ was calculated for Synechocystis which was considerably higher than the ones reported by Zijffers [13] for Chlorella sorokiniana (0.78 g mol photons $\left.^{-1}\right)$ and Dunaliella tertiolecta $(0.75 \mathrm{~g}$ mol photons ${ }^{-1}$ ). This discrepancy can be explained by the fact that absorbed light was used in our calculation, instead of total incident light. Another important difference was that, in our experiment, the incident light intensity was $1 / 6$ of the amount used by the said authors, and therefore our culture might have dissipated a very small amount of energy via NPQ.

Based on Pirt's model, LCE (PAR basis) yielded a maximum value of $12.5 \%$. This value was around $40 \%$ lower than the theoretical one (i.e., $18.95 \%$, Additional file 5: Text S1). The discrepancy between actual and theoretical LCE was very close to that calculated for the quantum yield of photosynthesis, $\Phi_{\mathrm{CO} 2}$ and to the maximum quantum yield of PSII $\left(F_{\mathrm{v}} / F_{\mathrm{m}}\right)$. This ratio was in fact lower than the one normally reported in higher plants and microalgae (0.75-0.85). It is conceivable that the photosynthetic apparatus of Synechocystis cells it normally stays in state 2 , which is characterized by lower fluorescence and photosynthesis rates and high energy dissipation via state transition quenching $(\mathrm{qT})$ [14]. $\mathrm{qT}$ is attributed to the decoupling of phycobilisomes from PSII [14]. It has been reported that phycobilisome decoupling is seemingly important not only under strong irradiation [15], but also at physiological conditions of irradiance, provided that the exposure time is sufficiently long. It has been suggested that the dissipation of light energy in Synechocystis may occur via both the orange carotenoid protein (OCP) [16] in blue actinic light and a rise in orange lightinduced S, M fluorescence [14].

The actual biomass yield ( $Y$, g mol photons ${ }^{-1}$ ) was relatively constant at most of the high $D$ (Table 1 ). Between minimum and maximum $D$ values, an increase in $Y$ of about $20 \%$ was observed. This could be attributed to the greater availability of light and to the higher growth yield $Y$. The highest biomass yield on light energy $\left(1.22 \pm 0.05 \mathrm{~g} \mathrm{~mol}\right.$ photons $\left.{ }^{-1}\right)$ was attained at $D=0.0725 \mathrm{~h}^{-1}$.

LCE values at different $D$ were fairly constant (mean $11.3 \pm 0.41 \%)$. Most likely, the efficient mixing system, consisting of a specially designed rotating impeller [17], and the absence of any dark zones in the reactor, prevented cells from becoming acclimated to low light even when they were grown at low $D$ (dense cultures). On the other hand, cells grown at a high $D$ reacted by reducing the chlorophyll antenna and increasing their optical 
absorption cross section, thus making better use of light per chlorophyll unit. In our culture system the photon flux uptake ranged from 16 to $95 \mathrm{mmol}$ photons $\mathrm{g}^{-1} \mathrm{~h}^{-1}$, with optimum value close to $50 \mathrm{mmol}$ photons $\mathrm{g}^{-1} \mathrm{~h}^{-1}$, that is, in correspondence to the highest LCE attained. These findings agree with the metabolic model proposed by Nogales et al. [18].

Both the maximum photochemical quantum yield $\left(F_{\mathrm{v}} / F_{\mathrm{m}}\right)$ and the effective quantum yield of PSII $(\Delta F /$ $\mathrm{F}_{\mathrm{m}}{ }^{\prime}$ ) declined by about $20 \%$ between minimum and maximum $D$. This occurrence was also accompanied by a slight increase in $V_{\mathrm{J}}$ of the chlorophyll fluorescence transient. A lower decrease in the ETR $\mathrm{Emax}_{\text {was recorded }}$ (about $10 \%$ at the extreme $D$ ). This lower difference compared to that observed in the effective quantum yield of PSII $\left(\Delta F / F_{\mathrm{m}}{ }^{\prime}\right)$ could be explained by the fact that with the increase of $D$ the cells reacted with a $40 \%$ increase in the chlorophyll optical absorption cross section. Despite the reduction in the $F_{\mathrm{v}} / F_{\mathrm{m}}$ ratio, gross photosynthesis (i.e. net photosynthesis plus respiration) did not show important changes and was found to be almost independent of $D$. Reductions in the net photosynthesis rate was compensated by a proportional increase in the respiration rate, which increased with increasing $D$. The apparent paradox of a reduction in the $F_{\mathrm{v}} / F_{\mathrm{m}}$ ratio without a parallel reduction in the maximum photosynthesis rate had already been reported by Behrenfeld et al. [19].

Quantum yield $\Phi_{\mathrm{CO} 2}$ determined in this study resulted higher (close to $0.06 \mathrm{~mol} \mathrm{CO}_{2} \mathrm{~mol}_{\text {photons }}{ }^{-1}$ ) in cells grown at lower $D$ (between 0.0173 and $0.0282 \mathrm{~h}^{-1}$ ). This value was close to that reported by Skillman [20] for C4 plants and that calculated by Nogales et al. using cyanobacteria system analysis [21]. The value slightly declined with the increase of $D$, which reduced the cell concentration and therefore led to a higher exposure of cells to light and consequently to a reduction in the effective quantum yield of PSII. Yet, these changes were not detected by changes in NPQ which was most likely underestimated due to the difficulty of correctly measuring $F_{\mathrm{m}}$ in dark adapted cultures of cyanobacteria. Moreover, in our calculation we assumed that PSII/PSI ratio was constant and equal to 1 . This ratio is close to the value reported by Fujimori et al. [22], who used Synechocystis cultures exposed to a constant light intensity similar to our experiments. However, PSII/PSI may range from 0.4 to 1.0 from low light-adapted to high light-adapted cultures [22, 23]. Much higher changes in the PSII/PSI ratio can be expected in carbon limited Synechocystis cultures as reported by Nogales [21]. PSII/PSI as low as 0.2 has been reported [24]. This unusual stoichiometry in cyanobacteria has been explained with the involvement of PSI in a significant amount of cyclic electron flow around this photosystem. Alternatively, high PSI amount in cyanobacteria may serve to balance the abundance of the respiratory electron transfer pathways into the PQ pool [25]. Both hypothesis are suggested to act as photoenergy-dissipation pathways [21, 25]. About $20 \%$ of electrons originated from water was targeted to $\mathrm{O}_{2}$ via Mehler reaction (water-water cycle) in wild type Synechocystis grown under atmospheric $\mathrm{CO}_{2}$ levels [26, 27].

\section{Conclusions}

The limited amount of available fossil energy on the one hand and the necessity: of gearing the economy towards low carbon emissions on the other, intensify the demand for clean energy sources for the near future. Synechocystis is a model system: thanks to its available genomic sequence and to its ability to be naturally transformable. It could provide renewable energy in the form of hydrogen, which is considered to be the most important energy carrier [3, 28]. Moreover, its use has been proposed for photosynthetic production of isoprene for various applications, such as the production of rubber, adhesives, plastics, and perfumes [5-7].

This study provides a significant data set analyzing the maximum threshold of LCE as well as basic bioenergetic parameters of high-density cultures of Synechocystis, a microorganism of immense biotechnological potential. Our experiments will help future attempts of genetic transformation of this organism and improve in silico analysis of cyanobacterial photosynthetic models.

We would like to emphasize that the mean effective LCE attained by Synechocystis in this study $(11.32 \pm 0.41 \%)$ was under strictly controlled laboratory conditions (refers to PAR from 400 to $700 \mathrm{~nm}$ ). Under more natural outdoor conditions with variable environmental factors (e.g., temperature, mixing, nutrients), the LCE, typically drops to 5-6\% of total solar radiation, of which PAR is assumed to account for $45 \%$. Similar LCE was also found by Zhu et al. for higher plants [29]. The culture studied in our lab was exposed to a light intensity which was roughly $1 / 10$ th of that recorded outdoors on a typical day in summer. Therefore, it would be unrealistic to compare laboratory performance of Synechocystis to outdoor culture scenarios.

\section{Methods}

\section{Photobioreactor set-up}

The system consisted of a 1 L Pyrex Roux-type culture bottle (950 mL working volume, $5 \mathrm{~cm}$ light path) with a flat cross section $(12 \times 5 \mathrm{~cm}$ width), a flat bottom, and four ports for the $\mathrm{pH}$ meter electrode, the medium inlet, the air $/ \mathrm{CO}_{2}$ inlet, and the cooling finger (Fig. 5). The main port at the top ( $2.5 \mathrm{~cm}$ i.d.) was sealed with a stopper equipped with tygon tubes for the outflow of culture and gases. Illumination was provided by means of cool 


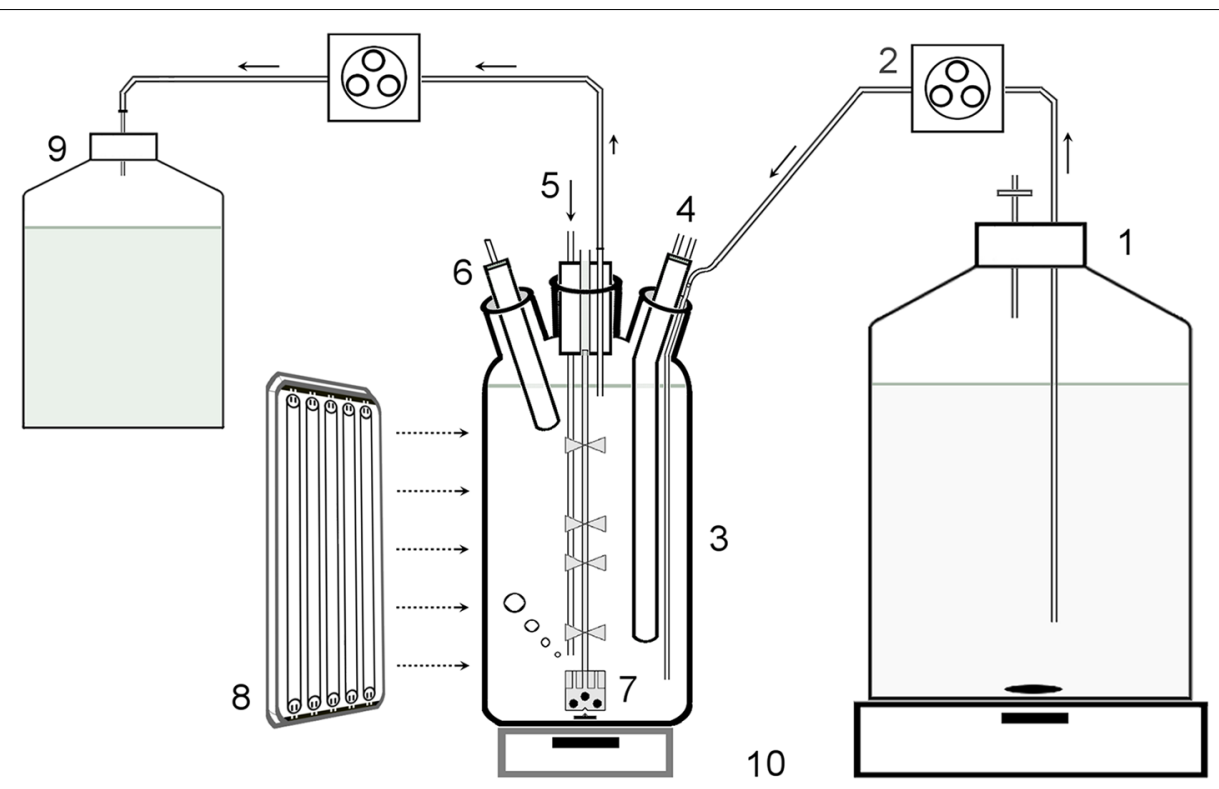

Fig. 5 Schematic representation of the experimental set-up for the continuous culture of Synechocystis. (1) medium inlet bottle, (2) peristaltic pump, (3) Roux-type bottle, (4) cooling finger, (5) Air/ $\mathrm{CO}_{2}$ inflow, (6) pH sensor, (7) impeller, (8) lamp panel, (9), harvest bottle, (10) magnetic stirrers

white lamps (Dulux L, $55 \mathrm{~W} / 840$, Osram, Italy) with a photon flux density (PFD) of $150 \mu \mathrm{mol}$ photons $\mathrm{m}^{-2} \mathrm{~s}^{-1}$. The PFD at the culture surface was measured with a flat quantum radio-photometer (LI-250A, LI-COR Biosciences). Mixing of the culture was achieved by means of a specially designed rotating impeller [17] driven magnetically by a stirrer at the bottom. A constant air flow was provided for the removal of oxygen, and a $\mathrm{pH}$ value of 7.4 was maintained by automatic addition of $\mathrm{CO}_{2}$. The air and $\mathrm{CO}_{2}$ were sterilized using $0.2 \mu \mathrm{m}$ pore size filters (Whatman, UK). The culture's temperature was maintained constant at $28.0 \pm 0.2{ }^{\circ} \mathrm{C}$ with the use of an external thermostat (MPM Instruments-Italy). For the medium inlet/outlet, two peristaltic pumps were used (Masterflex 7520-30 Cole Parmer for the medium inlet and SP311 Velp Scientifica for the medium outlet). The culture was assumed to be at a steady state when the cell concentration assessed with the dry weight method remained unchanged for at least $36 \mathrm{~h}$.

\section{Strains and medium}

The wild type Synechocystis strain PCC6803 was kindly provided by Prof. M. Rögner (Plant Biochemistry, Ruhr University Bochum, Germany). It was pre-cultured in a BG-11 medium under artificial light (intensity: $35 \mu \mathrm{mol}$ photons $\mathrm{m}^{-2} \mathrm{~s}^{-1}$ ) supplied from one side of the glass tube (cultivation columns) (i.d. $=50 \mathrm{~mm} ; 400 \mathrm{~mL}$ working volume). The cultures were bubbled with a mixture of air- $\mathrm{CO}_{2}(97 / 3 \mathrm{v} / \mathrm{v})$ at a continuous flow rate of
$5 \mathrm{dm}^{3} \min ^{-1}$. The growth was measured daily with the dry weight method.

\section{Culture characterization}

In a continuous culture system, cell growth is controlled by a continuous inflow of fresh sterile medium. The flow of fresh medium through the system is defined as dilution rate $D=F / V$, where $F\left(\mathrm{~mL} \mathrm{~L}^{-1} \mathrm{~h}^{-1}\right)$ is the flow rate of the fresh medium and $V(\mathrm{~L})$ is the culture volume. The change in biomass $\left(x, \mathrm{~g} \mathrm{~L}^{-1}\right)$ over time can be described as $\mathrm{d} x / \mathrm{d} t=$ growth-output, and $\mathrm{d} x / \mathrm{d} t=\mu x-D x$, where $\mu\left(\mathrm{h}^{-1}\right)$ is the specific growth rate.

When the cell concentration remains constant over time (steady state), i.e., $\mathrm{d} x / \mathrm{d} t \approx 0$, then $\mu=D$. The doubling time $t_{d}(\mathrm{~h})$ of the cells is given by the following equation: $t_{d}=\ln 2 / \mu$.

Productivity $P\left(\mathrm{mg} \mathrm{h}^{-1}\right)$ in continuous cultivation is dependent on the concentration of biomass $(X)$, and also on the dilution rate $(D)$. At the steady state, productivity is calculated as $P=\mu X V$.

Dry weight (DW) was determined in duplicate by using $10 \mathrm{~mL}$ samples taken from the PBR every day. Each sample was filtered through a pre-weighted $47 \mathrm{~mm}$ diameter glass microfiber filter membrane (Whatman GF/F filters, Maidstone, England). The cells were washed twice with deionized water the filters were then oven-dried at $105{ }^{\circ} \mathrm{C}$ to a complete evaporation (usually within $3 \mathrm{~h}$ ) and weighed. Lyophilized biomass was obtained from frozen samples $\left(-40^{\circ} \mathrm{C}\right)$ using a 5PASCAL LIO10P instrument 
(24 $\mathrm{h}$ at $0.1 \mathrm{mbar}$ ). The elemental composition analysis of the biomass was performed using a CHNOS Analyzer, Flash EA, 1112 Series (Thermo Electron Corporation). The ash content was determined by heating the biomass at $450{ }^{\circ} \mathrm{C}$ for $24 \mathrm{~h}$.

\section{Fluorescence measurements}

Chlorophyll a fluorescence transients were recorded using a Handy PEA (Hansatech Instruments, UK) in $2 \mathrm{~mL}$ dark adapted samples that were illuminated with continuous light (650 nm peak wavelength, $3500 \mu \mathrm{mol}$ photons $\mathrm{m}^{-2} \mathrm{~s}^{-1}$ ) provided by light-emitting diodes (LEDs). Each chlorophyll a fluorescence induction curve was analyzed using "BiolyzerHP3" software. The following parameters were calculated from the fluorescence measurements:

- $\quad$ minimum fluorescence yield, $F_{0}$, recorded at $50 \mu \mathrm{s}$;

- maximum fluorescence yield, $F_{\mathrm{m}}$;

- $M_{0}=4\left(F_{300 \mu \mathrm{s}}-F_{0}\right) /\left(F_{\mathrm{m}}-F_{0}\right)$, which corresponded to the net rate of the reaction center closure, where it increases by means of trapping and decreases by means of electron transport;

- the variable fluorescence at phase J, $V_{\mathrm{J}}=\left(F_{\mathrm{J}}-F_{0}\right) /$ $\left(F_{\mathrm{m}}-F_{0}\right)$, which is considered to be a good indicator of the plastoquinone pool redox state;

- the maximum quantum yield of photosystem II (PSII) for primary photochemistry, $\Phi\left(P_{0}\right)$, calculated as $F_{\mathrm{v}} / F_{\mathrm{m}}=\left(F_{\mathrm{m}}-F_{0}\right) / F_{\mathrm{m}}$;

- the quantum yield of the electron transport $\Phi_{\mathrm{E} 0}$, $\Phi_{\mathrm{E} 0}=\Phi\left(P_{0}\right) \times \Psi_{0}$, where $\Psi_{0}$ is the efficiency with which a trapped exciton can move an electron further than $Q_{\mathrm{A}}^{-}$(primary quinone electron acceptor) into the electron transport chain;

- the parameter $S_{\mathrm{m}}$, a measurement of the energy needed to reduce $Q_{\mathrm{A}}$ completely, was calculated by dividing the area by $F_{\mathrm{v}}$.

Slow kinetic analysis of chlorophyll fluorescence was performed using a pulse-amplitude-modulation fluorometer (PAM-2100, H. Walz, Effeltrich, Germany) operated by means of PamWin (version 2.00f) PC software. The ratio between variable and maximum fluorescence, $F_{\mathrm{v}} / F_{\mathrm{m}}$, was then measured to determine the maximum photochemical yield of PSII. For this purpose, samples were taken from the PBR and incubated in the dark for $15 \mathrm{~min}$ to remove any energy-dependent quenching. In addition, one far-red light (above $700 \mathrm{~nm}$ ) pulse with a duration of $10 \mathrm{~s}\left(10 \mathrm{~W} \mathrm{~m}^{-2}\right)$, supplied by the PAM-2100, was applied. For comparison, measurements of $F_{\mathrm{v}} / F_{\mathrm{m}}$ were also performed in the light using 3-(3,4-dichlorophenyl)-1,1-dimethylurea (DCMU) $\left(10^{-5} \mathrm{M}\right)$, and resulted in a lower value, therefore all the measurements were carried out under far-red light. The photochemical quantum yield of PSII in the light-adapted state, i.e., when the PSII reaction centers are open $\left(F_{\mathrm{v}}{ }^{\prime} / F_{\mathrm{m}}{ }^{\prime}\right)$, was calculated by using the variable fluorescence $\left(F_{\mathrm{v}}{ }^{\prime}=F_{\mathrm{m}}{ }^{\prime}-F_{0}{ }^{\prime}\right)$ and the maximum fluorescence from the light-adapted culture $\left(F_{\mathrm{m}}{ }^{\prime}\right)$. $F_{v}^{\prime} / F_{\mathrm{m}}{ }^{\prime}$ indicates the proportion of light-absorbed by PSII that is potentially usable for photochemistry in the light. The effective photochemical quantum yield of PSII $\Delta F / F_{\mathrm{m}}{ }^{\prime}=\left(F_{\mathrm{m}}{ }^{\prime}-F_{\mathrm{s}}\right) / F_{\mathrm{m}}{ }^{\prime}$, which is the number of electrons generated per photon absorbed [30], was measured using $F_{\mathrm{s}}$ and $F_{\mathrm{m}}$, which represented the steady-state and maximum fluorescence measured in the light. $F_{\mathrm{s}}$ and $F_{\mathrm{m}}{ }^{\prime}$ were determined by putting the fiber-optic probe of the fluorometer directly in contact on the illuminated PBR surface at an angle of $60^{\circ}$. Non-photochemical quenching (NPQ) was calculated by using the Stern-Volmer equation NPQ $=\left(F_{\mathrm{m}}-F_{\mathrm{m}}{ }^{\prime}\right) / F_{\mathrm{m}}{ }^{\prime}[31] . F_{0}{ }^{\prime}$ was estimated from the following relationship: $F_{0}{ }^{\prime}=F_{0} /\left[F_{\mathrm{v}} / F_{\mathrm{m}}+F_{\mathrm{o}} / F_{\mathrm{m}}{ }^{\prime}\right]$ [32]. The photochemical quenching (qP) was calculated according to Kromkamp and Forster [33].

\section{Cross section and electron transport rate}

The average chlorophyll specific optical absorption cross section $\left(a^{*}\right)$ of the cells was determined according to Kromkamp and Limbeek [34] from in vivo absorption spectra (range 400-750 $\mathrm{nm}$ ) recorded on a Varian Cary50 UV-visible spectrophotometer. To minimize the impact of the light scattering effect from the cells' surface on the absorbance measurement, the sample in the cuvette was positioned right next to the detector window.

The photosynthetic electron transport rate of PSII (ETR, $\mu \mathrm{mol} \mathrm{e} \mathrm{mg} \mathrm{chl}^{-1} \mathrm{~s}^{-1}$ ) was estimated from the following relationship:

$$
\mathrm{ETR}=\Delta F / F_{\mathrm{m}}^{\prime} \times \mathrm{PAR} \times a^{*} \times 0.5
$$

assuming that the photosystem I (PSI) to PSII (PSI/PSII) ratio of Synechocystis PCC6803 is 1 according to Fujimori et al. [22]. Thus, $50 \%$ of the photons are absorbed by PSII [35], and $a^{*}\left(\mathrm{~m}^{2} \mathrm{mg} \mathrm{chl}{ }^{-1}\right)$ was the average chlorophyll optical cross section normalized to chlorophyll a. This equation assumes that no cyclic electron transport by PSI occurs.

The quantum yield of $\mathrm{CO}_{2}$ assimilation, $\Phi_{\mathrm{CO} 2}$, was calculated from the product of $\Phi$ PSII $\times$ fraction PSII $\times(1 / 4)[36]$ where $\Phi_{\text {PSII }}=\Delta F / F_{\mathrm{m}}{ }^{\prime}$.

\section{Oxygen evolution measurements}

Oxygen evolution measurements were carried out in triplicate on $2 \mathrm{~mL}$ culture samples (chlorophyll content: $\left.5 \mathrm{mg} \mathrm{L}^{-1}\right)$, using a Liquid-Phase Oxygen Electrode Chamber (Hansatech, DW3) thermostated at $28{ }^{\circ} \mathrm{C}$ and equipped with an oxygen control electrode unit (Hansatech, Oxy-lab). Light was supplied via a red LED light 
source (Hansatech LH36/2R) at $637 \mathrm{~nm}$ wavelength providing a $500 \mu \mathrm{mol}$ photons $\mathrm{m}^{-2} \mathrm{~s}^{-1}$ PFD. The $\mathrm{O}_{2}$ concentration dissolved in the sample was continuously monitored at an acquisition rate of 0.2 reads $\mathrm{s}^{-1}$. Dark respiration rates were measured after the photosynthesis rates had been measured.

\section{Chlorophyll and carotenoid analysis}

Chlorophyll concentration was determined spectrophotometrically in triplicate samples. $5 \mathrm{~mL}$ samples were centrifuged in glass tubes for $8 \mathrm{~min}$ at $2650 \mathrm{~g}$ in an ALCPK110 centrifuge. The supernatant was discarded, and the pellet was resuspended in $5 \mathrm{~mL}$ of pure methanol. The tubes were then placed in a $70{ }^{\circ} \mathrm{C}$ water bath for $3 \mathrm{~min}$, and centrifuged again for $8 \mathrm{~min}$ at $2650 \mathrm{~g}$. The supernatant absorbance was measured at 665 and $750 \mathrm{~nm}$ against a pure methanol blind. The concentrations of individual carotenoids were assessed using a reversed-phase Beckman System Gold HPLC (module 125 solvent) equipped with a diode array detector, model 168 Nouveau (Beckman Instruments, Inc., CA, USA), with a column Luna, C8 (Phenomenex), in accordance with Van Heukelem and Thomas [37].

\section{Protein, carbohydrate and lipid contents}

Protein determination was performed according to Lowry [38]. The total carbohydrate content was measured using the phenol-sulfuric acid method [39], with $D+$ glucose used as the standard. Lipids were extracted from $5 \mathrm{mg}$ of dry biomass using $1 \mathrm{~mL}$ of dichloromethane, $2 \mathrm{~mL}$ of methanol and $0.8 \mathrm{~mL}$ of deionized water $(1: 2: 0.8, \mathrm{v} / \mathrm{v} / \mathrm{v})$. The mixture was vortexed and sonicated for $10 \mathrm{~min}$, after which an additional $1 \mathrm{~mL}$ of dichloromethane and $1 \mathrm{~mL}$ of deionized water were added. The mixture was then vortexed and centrifugated for $5 \mathrm{~min}$ at $1500 \mathrm{~g}$ (ALC-PK110). The bottom phase was recovered, placed in pre-weighted containers, and heated to complete evaporation. The extracted lipids were then weighed. The analyses were performed in triplicate. The heat of combustion $\left(\mathrm{kJ} \mathrm{g}^{-1}\right)$ of the biomass at the steady-state of each $D$ was calculated by using the formula:

$$
\begin{aligned}
& ([(\text { proteins } \times 5.7)+(\text { carbohydrates } \times 4.2) \\
& \quad+(\text { lipids } \times 9.3)] / 100) \times 4.184 .
\end{aligned}
$$

Amino acid composition was determined according to Potenza et al. [40].

\section{Phycocyanin extraction and determination}

Culture samples $(5 \mathrm{~mL})$ were collected in tubes and centrifuged at $2650 \mathrm{~g}$ for $8 \mathrm{~min}$. The supernatant was discarded, and $0.5 \mathrm{~mL}$ of glass beads (diameter $0.17-0.18 \mathrm{~mm}, \mathrm{~B}$. Braun Biotech Int-Germany) were added to the sample, along with $200 \mu \mathrm{L}$ of $\mathrm{NaCl} 0.15 \mathrm{M}$ phosphate-buffered (pH 7.4) solution. The mixture was vortexed for $10 \mathrm{~min}$ to break down the cells; thereafter, phosphate buffer was then added to reach $5 \mathrm{~mL}$ of final volume. The tubes were centrifuged at $2650 \mathrm{~g}$ for $5 \mathrm{~min}$, the supernatant was then transferred into $15 \mathrm{~mL}$ Falcon tubes and centrifuged at $12500 \mathrm{~g}$ for $10 \mathrm{~min}$. The absorbance values at $652 \mathrm{~nm}$ (allophycocyanin) and $615 \mathrm{~nm}$ (phycocyanin) were measured, after which the concentrations of allophycocyanin and phycocyanin were calculated according to Bennett and Bogorad [41]. The measurements were performed in duplicate.

\section{Additional files}

Additional file 1: Figure S1. The maximum quantum yield of PSII ( $F_{v}$ / $F_{m}$ ) and $\Delta F / F_{m}{ }^{\prime}$ of Synechocystis as a function of the dilution rate.

Additional file 2: Table S1. The $M_{0}$ (initial slope at the beginning of the variable fluorescence), $V_{J}$ (the variable fluorescence at phase J), $\Phi_{E 0}$ (the quantum yield of electron transport), $\Psi_{0}$ (the efficiency with which a trapped exciton can move an electron further than $\mathrm{Q}_{A}^{-}$into the electron transport chain) and the parameter $S_{m}$ of Synechocystis in a continuous culture. Values are mean \pm standard deviations calculated over the steady state for each dilution rate.

Additional file 3: Table S2. Elemental composition of Synechocystis dried biomass, cultured at different dilution rates. Values are mean \pm standard deviations calculated during the steady state at each $D\left(\mathrm{~h}^{-1}\right)$.

Additional file 4: Table S3. Comparison of amino acid composition of Synechocystis cultured at three different dilution rates.

Additional file 5: Text S1. Theoretical biomass yield on light energy calculation.

\section{Abbreviations}

A: illuminated reactor surface area $\left(\mathrm{m}^{2}\right)$; $X$ : biomass concentration $\left(\mathrm{g} \mathrm{L}^{-1}\right)$; D: dilution rate $\left(\mathrm{h}^{-1}\right)$; E: mean energy content of one mol of photons in the visible spectra ( $\mathrm{kJ}$ mol photons ${ }^{-1}$ ); LCE: light conversion efficiency (-); M: biomass maintenance coefficient (mol photons $\mathrm{g}^{-1} \mathrm{~h}^{-1}$ ); PAR: photosynthetic active radiation ( $\mu \mathrm{mol}$ photons $\mathrm{m}^{-2} \mathrm{~s}^{-1}$ ); $\mathrm{qL}$ : specific rate of absorption of radiation (mol photons $\left.\mathrm{g}^{-1} \mathrm{~h}^{-1}\right) ; \mu$ : growth rate $\left(\mathrm{h}^{-1}\right) ; \mathrm{V}$ : volume of the bioreactor $(\mathrm{L})$; $Y$ : actual biomass growth yield on light-absorbed energy ( $\mathrm{g} \mathrm{mol} \mathrm{photons}^{-1}$ ); $Y_{G}$ : maximum attainable biomass growth yield on light-absorbed energy ( $\mathrm{g} \mathrm{mol}$ photons ${ }^{-1}$ ); $\phi$ : fraction of PAR absorbed by cultures (-); AEF: alternative electron flow; PQ: plastoquinone pool.

\section{Authors' contributions}

GT designed the experiments. ET and BC set up the experiments and performed the analyses while GT and ET analyzed the data. All authors read and approved the final manuscript.

\section{Acknowledgements}

We thank Dr. C. Faraloni for her technical assistance with the HPLC analysis, Mr. S. Dodero and E. Pinzani for their technical assistance with the CHNOS elemental analysis and K.G. Srikanta Dani for manuscript editing. The research leading to these results has received funding from the European Union Seventh Framework Programme (FP7/2007-2013) under Grant agreement number 308518 (CyanoFactory). Amino acid composition analysis performed by PeptLab (http://www.peptlab.eu/).

\section{Compliance with ethical guidelines}

Competing interests

The authors declare that they have no competing interests. 
Received: 6 February 2015 Accepted: 18 August 2015 Published online: 04 September 2015

\section{References}

1. Gao Z, Zhao H, Li Z, Tan X, Lu X (2012) Photosynthetic production of ethanol from carbon dioxide in genetically engineered cyanobacteria. Energy Environ Sci 5:9857-9865

2. Yu Y, You L, Liu D, Hollinshead W, Tang YJ, Zhang F (2013) Development of Synechocystis sp. PCC6803 as a phototrophic cell factory. Mar Drugs 11(8):2894-2916

3. Quintana N, Van der Kooy F, Van de Rhee MD, Voshol GP, Verpoorte R (2011) Renewable energy from cyanobacteria: energy production optimization by metabolic pathway engineering. Appl Microbiol Biotechnol 91:471-490

4. Baebprasert W, Jantaro S, Khetkorn W, Lindblad P, Incharoensakdi A (2011) Increased $\mathrm{H}_{2}$ production in the cyanobacterium Synechocystis sp. strain PCC6803 by redirecting the electron supply via genetic engineering of the nitrate assimilation pathway. Metab Eng 13:610-616

5. Linderberg P, Park S, Melis A (2010) Engineering a platform for photosynthetic isoprene production in cyanobacteria, using Synechocystis as the model organism. Metabolic Eng 12:70-79

6. Melis A (2012) Photosynthesis-to-fuels: from sunlight to hydrogen, isoprene, and botryococcene production. Energy Env Sc 5:5531-5539

7. Chaves JE, Kirst H, Melis A (2015) Isoprene production in Synechocystis under alkaline and saline growth conditions. J Appl Phycol 27:1089-1097

8. Kwon JH, Rögner M, Rexroth S (2012) Direct approach for bioprocess optimization in a continuous flat-bed photobioreactor system. J Biotechnol 162:156-162

9. Vonshak A, Laorawat S, Bunnag B, Tanticharoen M (2014) The effect of light availability on the photosynthetic activity and productivity of outdoor cultures of Arthrospira platensis (Spirulina). J Appl Phycol 26:1309-1315

10. Torzillo G, Vonshak A (2013) Environmental stress physiology with reference to mass cultures. In: Richmond A, Hu Q (eds) Handbook of microalgal cultures. Blackwell Science Ltd, Oxford

11. Lee KY, Pirt SJ (1981) Energetics of photosynthetic algal growth: influence of intermittent illumination in short (40 s) cycles. J Gen Microbiol 124:43-52

12. Pirt SJ (1986) The thermodynamic efficiency (quantum demand) and dynamics of photosynthetic growth. New Phytol 102:3-37

13. Zijffers J-WF, Schippers KJ, Zheng K, Janssen M, Tramper J, Wijffels RH (2010) Maximum photosynthetic yield of green microalgae in photobioreactors. Mar Biotechnol 12(6):708-718

14. Kaña R, Kotabová E, Komárek O, Šedivá B, Govindjee PC, Prášil O (2012) The slow $\mathrm{S}$ to $\mathrm{M}$ fluorescence rise in cyanobacteria is due to a state 2 to state 1 transition. Biochim Biophys Acta 1817:1237-1247

15. Tamary E, Kiss V, Nevo R, Adam Z, Bernàt G, Rexroth S (2012) Structural and functional alterations of cyanobacterial phycobilisomes induced by high-light stress. Biochim Biophys Acta 1817:319-327

16. Wilson A, Ajlani G, Verbavatz JM, Vass I, Kerfeld CA, Kirilowsky D (2006) A soluble carotenoid protein involved in phycobilisome-related energy dissipation in cyanobacteria. Plant Cell 18:992-1007

17. Giannelli L, Scoma A, Torzillo G (2009) Interplay between light intensity, chlorophyll concentration and culture mixing on the hydrogen production in sulfur-deprived Chlamydomonas reinhardtii cultures grown in laboratory photobioreactors. Biotechnol Bioeng 104:76-90

18. Nogales J, Gudmundsson S, Thiele I (2013) Toward systems metabolic engineering in cyanobacteria. Bioengineered 4(3):158-163

19. Behrenfeld M, Prasil O, Kolbert ZS, Babin M, Falkowsky PG (1988) Compensatory changes in photosystem II electron turnover rates protect photosynthesis from photoinhibition. Photos Res 58:259-268

20. Skillman JB (2008) Quantum yield variation across the three pathways of photosynthesis: not yet out of the dark. J Exp Bot 59(7):1647-1661

21. Nogales J, Gudmundsson S, Knight EM, Palsson BO, Thiele I (2012) Detailing the optimality of photosynthesis in cyanobacteria through systems biology analysis. PNAS 109:2678-2683
22. Fujimori T, Higuchi M, Sato H, Aiba H, Muramatsu M, Hihara Y, Sonoike K (2005) The mutant of sll1961, which encodes a putative transcriptional regulator, has a defect in regulation of photosystem stoichiometry in the cyanobacterium Synechocystis sp. PCC 6803. Plant Physiol 139:408-416

23. Ozaki H, Ikeuchi M, Ogawa T, Fukuzawa H, Sonoike K (2007) Large-scale analysis of chlorophyll fluorescence kinetics in Synechocystis sp. PCC 6803: identification of the factors involved in the modulation of photosystem stoichiometry. Plant Cell Physiol 48(3):451-458

24. Shen G, Boussiba S, Vermaas WFJ (1993) Synechocystis sp. PCC 6803 strains lacking photosystem I and phycobilisome function. Plant Cell 5:1853-1863

25. Vermaas WFJ (2001) Photosynthesis and respiration in cyanobacteria. In: Encyclopedia of life sciences. Nature Publishing Group: London, pp 245-251

26. Allahverdiyeva $Y$, Ermakova $M$, Eisenhut $M$, Zhang PP, Richaud $P$, Hagemann M, Cournac L, Aro EM (2011) Interplay between flavodiiron proteins and photorespiration in Synechocystis sp. PCC 6803. J Biol Chem 286:24007-24014

27. Asada K (2000) The water-water cycle as alternative photon and electron sinks. Philos Trans R Soc Lond B Biol Sci 355(1402):1419-1431

28. Ghirardi ML, Mohanty P (2010) Oxygenic hydrogen photoproductioncurrent status of the technology. Curr Sci 98:499-507

29. Zhu XG, Long SP, Ort DR (2008) What is the maximum efficiency with which photosynthesis can convert solar energy into biomass? Curr Opin Biotech 19:153-159

30. Hofstraat JW, Peeters JHC, Snel JH, Geel C (1994) Simple determination of photosynthetic efficiency and photoinhibition of Dunaliella tertiolecta by saturating pulse fluorescence measurements. Mar Ecol-Progr Ser 103:187-196

31. Krause GH, Jahns P (2004) Non-photochemical energy dissipation determined by chlorophyll fluorescence quenching: characterization and function. In: Papageorgiou GC, Govindjee (eds) Chlorophyll a fluorescence. Advances in photosynthesis and respiration, Kluwer Academic Publishers: Dordrecht, pp 463-495

32. Oxborough K, Baker NR (1997) Resolving chlorophyll a fluorescence images of photosynthetic efficiency into photochemical and non-photochemical components - calculation of $\mathrm{qP}$ and $F_{\mathrm{v}}{ }_{\mathrm{v}} / F_{\mathrm{m}}{ }^{\prime}$ without measuring Fo'. Photosynth Res 54:135-142

33. Kromkamp JC, Forster RM (2003) The use of variable fluorescence measurements in aquatic ecosystems: differences between multiple and single turnover measuring protocols and suggested terminology. Eur J Phycol 38:103-112

34. Kromkamp J, Limbeek M (1993) Effect of short-term variation in irradiance on light harvesting and photosynthesis of the marine diatom Skeletonema costatum: a laboratory study simulating vertical mixing. J Ge Microbiol 139:2277-2284

35. Genty B, Briantais J-M, Baker NR (1989) The relationship between the quantum yield of photosynthetic electron transport and quenching of chlorophyll fluorescence. Biochim Biophys Acta 990:87-92

36. Baker NR (2008) Chlorophyll fluorescence: a probe of photosynthesis in vivo. Annu Rev Plant Biol 59:89-113

37. Van Heukelem L, Thomas CS (2001) Computer-assisted high performance liquid chromatogaphy method development with applications to the isolation and analysis of phytoplankton pigments. J Chromatogr A 910:31-49

38. Lowry O, Rosebrough N, Farr A, Randall R (1951) Protein measurement with the Folin phenol reagent. J Biol Chem 193:265-275

39. Dubois M, Gilles K, Hamilton J, Rebers P, Smith F (1956) Colorimetric method for determination of sugars and related substances. Anal Chem 28(3):350-356

40. Potenza M, Sabatino G, Giampi F, Rosi L, Papini AM, Dei L (2013) Analysis of egg-based model wall paintings by use of an innovative combined dot-ELISA and UPLC-based approach. Anal Bioanal Chem 405:691-701

41. Bennett A, Bogorad $L$ (1973) Complementary chromatic adaptation in a filamentous blue-green alga. J Cell Biol 58(2):419-435 